\title{
Perturbed nuptiality, delayed fertility: childbirth effects of Covid19
}

\author{
Mazhar Mughal ${ }^{1} \cdot$ Rashid Javed $^{2,3}$ (D) \\ Accepted: 4 May 2021 / Published online: 18 August 2021 \\ (C) The Author(s), under exclusive licence to Springer Nature B.V. 2021
}

\begin{abstract}
An aspect of the Covid-19 pandemic that merits attention is its effects on marriage and childbirth. Although the direct fertility effects of people getting the virus may be minor, the impact of delayed marriages due to the first preventive lockdown, such as that imposed in Pakistan from March 14 to May 8 2020, and the closure of marriage halls that lasted till September 14 may be non-negligible. These demographic consequences are of particular import to developing countries such as Pakistan where birth rates remain high, marriage is nearly universal, and almost all child-bearing takes place within marriage. Based on historic marriage patterns, we estimate that the delay in nuptiality during the first wave of the coronavirus outbreak may affect about half of the marriages that were to take place during the year. In Pakistan, childbearing begins soon after marriage, and about $37 \%$ of Pakistani married women give birth to their first child within twelve months of marriage. A sizeable number out of these, around 400,000 annual births that occur within twelve months of the marriage, may consequently be delayed. Postponement of marriages due to the accompanying difficult economic situation and employment precariousness will accentuate this fertility effect. The net fertility impact of the Covid-19 outbreak will ultimately depend not only on the delay in marriages but also on the reproductive behavior of existing couples.
\end{abstract}

Keywords COVID-19 · Coronavirus $\cdot$ Lockdown $\cdot$ Nuptiality $\cdot$ Marriage $\cdot$ Fertility Childbirth $\cdot$ Pakistan

JEL codes $\mathrm{I} 10 \cdot \mathrm{I} 18 \cdot \mathrm{J} 10 \cdot \mathrm{J} 12 \cdot \mathrm{J} 13$

Rashid Javed

rachidjaved@gmail.com

Mazhar Mughal

mazhar.mughal@esc-pau.fr

1 Pau Business School, 64000 Pau, France

2 Westminster International University in Tashkent, 100047 Tashkent, Uzbekistan

3 Tree, University of Pau and Pays de l'Adour, 64000 Pau, France 


\section{Introduction}

A century after the Spanish Influenza, dubbed "Mother of all pandemics" (Taubenberger \& Morens, 2006) wreaked havoc across the planet, the Covid-19 pandemic is ravaging the human population. By 17th April 2021, over 3 million people have died and 141 million have been infected (Johns Hopkins University \& Medicine, 2020). These numbers, though tragically large, have so far been a fraction of the fatalities seen in the Spanish flu outbreak. Estimates of Spanish flu fatalities range from 17 to 100 million, or $1-6 \%$ of the world population at that time, with around $5 \%$ of British India's population perishing in the pandemic (Chandra \& Christensen, 2019; Johnson \& Mueller, 2002; Patterson \& Pyle, 1991; Spreeuwenberg et al., 2018). However, the economic losses of the Covid-19 pandemic are such not seen during peacetime for generations. Governments imposed preventive lockdowns and large parts of the global economy came to a halt. Demand for goods and services fell sharply, supply chains broke down as transportation and human mobility were seriously curtailed. As a result of the Great Lockdown caused by the pandemic, budget deficits and unemployment numbers soared to unprecedented levels and the spectre of recession loomed in countries across the world (Atkeson, 2020; IMF, 2020; McKibbin \& Fernando, 2020).

Another dimension of the pandemic that merits attention is its effects on marriage and childbirth. The coital frequency in the affected population may fall below average during the outbreak, either as a result of the illness's debilitating biological effects or for fear of contagion among the social survivors. The demographic consequences are of particular import to developing countries where birth rates remain high, marriage is nearly universal, and almost all child-bearing takes place within marriage. The South Asian country of Pakistan, for instance, has a Total Fertility Rate (TFR) of 3.6 and a population growth rate of 2.1\% (World Bank, 2018). According to data from a pooled sample of four rounds of the Pakistan Demographic and Health Survey (PDHS 1990-91, 2006-07, 2012-13 and 2017-18), 313 women out of a total of 39,786 Pakistani women with at least one child reported giving birth prior to marriage. This corresponds to $0.79 \%$ of firstborn births in Pakistan.

A year since the Covid-19 pandemic began spreading in Pakistan and other countries of South Asia, the region's infection-related mortality rates, at less than one death per thousand population, are lower than those seen in the worst-hit regions such as Latin America and Europe (Johns Hopkins University \& Medicine, 2020). Pakistan, a country with a population of 216 million (World Bank, 2019), has suffered 16,094 reported deaths due to novel coronavirus by 17th April 2021, corresponding to one death per 13,456 individuals. Likewise, the numbers of persons affected by the virus remained below one in hundred, with 750,158 persons (about $0.35 \%$ of the country's population) testing positive to coronavirus. ${ }^{1}$

Given this relatively low infection rate during the first year of the pandemic, the direct impact on fertility from persons getting the virus may be minor. The fact that

1 The lower numbers may, in part, also owe to lower testing of the population. 
an overwhelming majority of those who have died due to coronavirus have been the elderly, often those with one or more co-morbidities, and that relatively-few young adults have died should also limit any direct effect on fertility. However, the impact on nuptiality and fertility arising from the preventive lockdown may well prove to be substantial. In this study, we discuss the delay in marriage caused by the ban on public gatherings and the closure of wedding halls during the first lockdown imposed by the Government of Pakistan. During the preventive lockdown that began from 13 March 2020, all educational institutions and places of public gathering including marriage halls and sport stadia were closed and public events were cancelled. Though some restrictions were relaxed starting from May 9 2020, public gatherings remain prohibited until 14th September 2020. The closure of marriage halls, banquets, and marquees during this six month period (13 March-14 September 2020) led to postponement or cancellation of ceremonies during the prime wedding season. We analyse possible fertility impacts of the resulting delay in marriages and report some preliminary findings in light of the developing scenario.

\section{Covid-19 situation in Pakistan}

On 26 February 2020, Pakistan confirmed its first two cases of the novel coronavirus. The country announced the first phase of comprehensive nation-wide lockdown on March 13 2020. At that time, there were 33 confirmed coronavirus cases but no reported death in the country. Within one month of the virus' arrival, the number of total confirmed cases (COVID-19 Positive) in the country reached 1,057. All of the initial confirmed cases had recent travel history from Europe or Iran. The country reported its first death from coronavirus on March 20 2020. During the second month (March 26-April 26), the number of confirmed cases jumped to 12,723, with 269 reported fatalities (Government of Pakistan, 2020a). A large religious congregation that took place near Lahore, the country's second largest city, prior to the lockdown played a major role in spreading the virus. About $27 \%$ of Pakistan's Covid-19 cases can be traced to this mass congregation. Within three months of the first reported case (May 26 2020), the number of COVID-19 positive cases reached 57,705 , with 1,197 reported deaths.

A new spike was observed around the festival of Eid-al-fitr (May 24). On the 18th of May 2020, the Supreme Court of Pakistan ordered the federal and provincial governments to open all malls and shopping centres in order to allow shopping for the festival. Mass violations of standard operating procedures (SOP) devised by the government were observed during the period leading to an exponential growth in infections. By mid-June, a peak was reached with 6,825 new cases reported on 15 th June 2020, after which a steady decline was observed. On the 2nd July, recoveries from the infection exceeded active cases for the first time. Six months since the first reported case (August 26 2020), the total number of positive cases reached 294,193 with 8,987 active cases and 6,267 reported deaths. By September 2020, Pakistan had managed to control the outbreak; new cases during the month were consistently below 1,000 and the daily death count was in the single figures. By the end of the month, the total number of deaths stood at 6,484 . 
The marriage halls were allowed to open from 14th September 2020, and large numbers of delayed marriages took place during the subsequent weeks. However, mass violations of coronavirus SOPs turned large weddings into virus super-spreaders. In mid-October, the government limited the timings of marriage halls and the number of guests amidst fears of a second wave of the coronavirus pandemic. By late October 2020, the country was in the grip of the second wave. In response, the government closed down schools and universities, reduced the timings of markets, restaurants, and marriage halls, and enforced smart lockdowns in worst-affected areas. In mid-November, new daily cases touched the two thousand mark. The peak of this wave, which proved to be milder than the first one, was reached on 6th December 2020 when 3,795 new daily cases were recorded. On 26th February 2021, exactly 1 year since the first coronavirus case was reported in Pakistan, the number of Covid-19 positive cases had reached 578,797 with 12,837 reported deaths.

After the relatively calm months of January and February 2021, coronavirus cases again began to increase rapidly in March. Punjab, the most populous province, banned indoor weddings from 15th March 2021. From 5th April 2021, wedding ceremonies were banned in all the districts of the country where the test positivity rate was above $8 \%$. Additionally, all educational institutions were closed down in 18 high-risk districts. By 17th April 2021, the number of daily positive cases had reached 4,976 with 112 deaths recorded in the previous $24 \mathrm{~h}$. In this wave, that proved more virulent and deadly than the previous two, even the country's top leadership was affected with both the President and the Prime Minister getting infected.

Overall, the outbreak has affected the population across the country. The highest numbers of infections were reported in the two more populous provinces of Sindh and Punjab with 269,840 and 255,571 confirmed cases respectively.

\section{Data}

The data used in this paper come from the Pakistan Demographic and Health Survey (PDHS), a nation-wide representative survey that contains comprehensive information on child and woman health, birth histories, birth durations, family planning, gender preference, use of contraceptives, domestic violence, employment, and other demographic and socio-economic characteristics of women, their husbands, and their households. The PDHS surveys are based on a two-stage stratified strategy and are carried out by the National Institute of Population Studies (NIPS), Islamabad with technical and financial assistance from the US Agency for International Development (USAID). We employ the fourth and latest round of PDHS, i.e., PDHS 2017-2018. The sample for this survey is representative at the national level as well as for urban and rural areas, the four provinces (Punjab, Sindh, Khyber Pakhtunkhwa, and Balochistan), Azad Jammu and Kashmir (AJK), Gilgit Baltistan (GB), the Islamabad Capital Territory (ICT) and the erstwhile Federally Administered Tribal Areas (FATA). For this round, the country was divided into 580 Primary Sampling Units (PSU), 285 in urban areas and 295 in rural areas. 15,068 women from 14,540 households were covered with a total of 50,495 corresponding children. This nation-wide survey of substantial size carried out in 2017-18 provides us the 


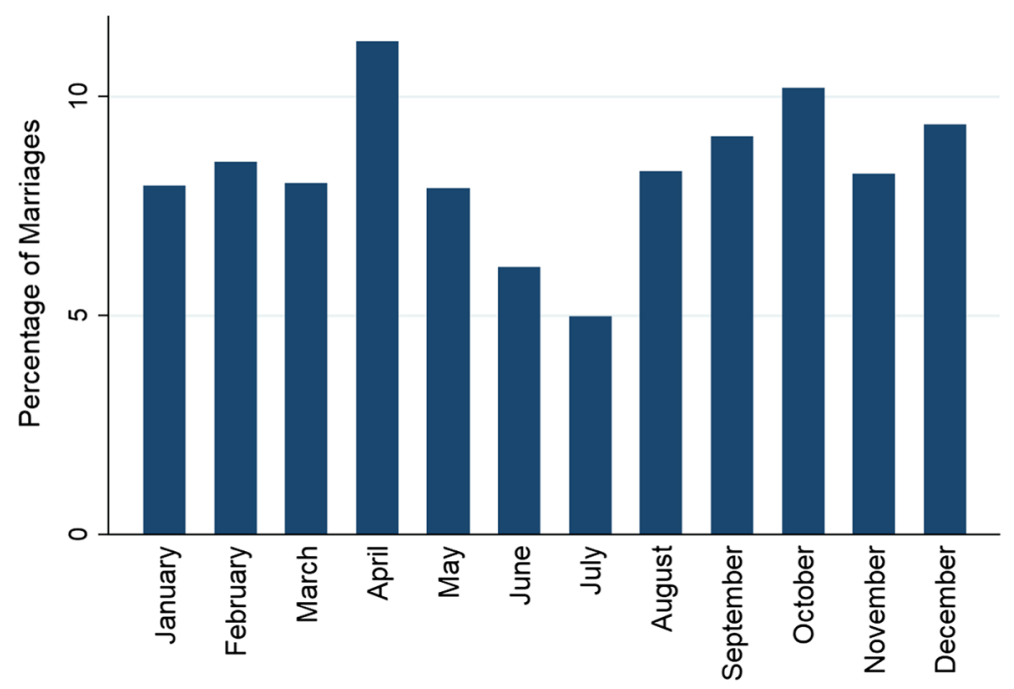

Source: Authors' calculations using PDHS 2017-18. Observations pertaining to the incomplete survey year 2018 have been excluded

Fig. 1 Marriage distribution by month (2013-2017)

latest available demographic data as well as recent marriage and fertility patterns, which can be used to understand possible changes taking place during the Covid-19 pandemic.

\section{Seasonality of nuptial arrangements}

In the Pakistani culture, the marriage contract (called Nikah) can take place at home (or even online or by telephone) in the presence of a handful of participants from the two sides. However, marriage is generally not consummated without a formal public ceremony called Rukhsati. Weddings are an elaborate set of ceremonies that last several days and are attended by hundreds (or occasionally thousands) of guests. Spring has historically been the preferred season for marriages (Suleman, 1985). The weather at that time of year is pleasant, schools are closed after annual examinations, and the harvest of wheat, the country's principal winter crop, begins. Relatively few wedding ceremonies are carried out during summer months. In the month of June, the hottest month in the country, temperatures in the plains of Indus valley regularly rise to $40{ }^{\circ} \mathrm{C}\left(104^{\circ} \mathrm{F}\right)$ or even higher. The months of July and August are hot and humid as the country receives frequent, occasionally heavy Monsoon rains. Nevertheless, households whose family members have migrated abroad tend to arrange weddings during the summer vacations in order to accommodate the migrant participants. Figure 1 shows the distribution by months of marriage for 3,311 women who married between 2013 and 2017 as reported in the 2017-18 Pakistan Demographic and Health Survey (PDHS). April, October, and December are 


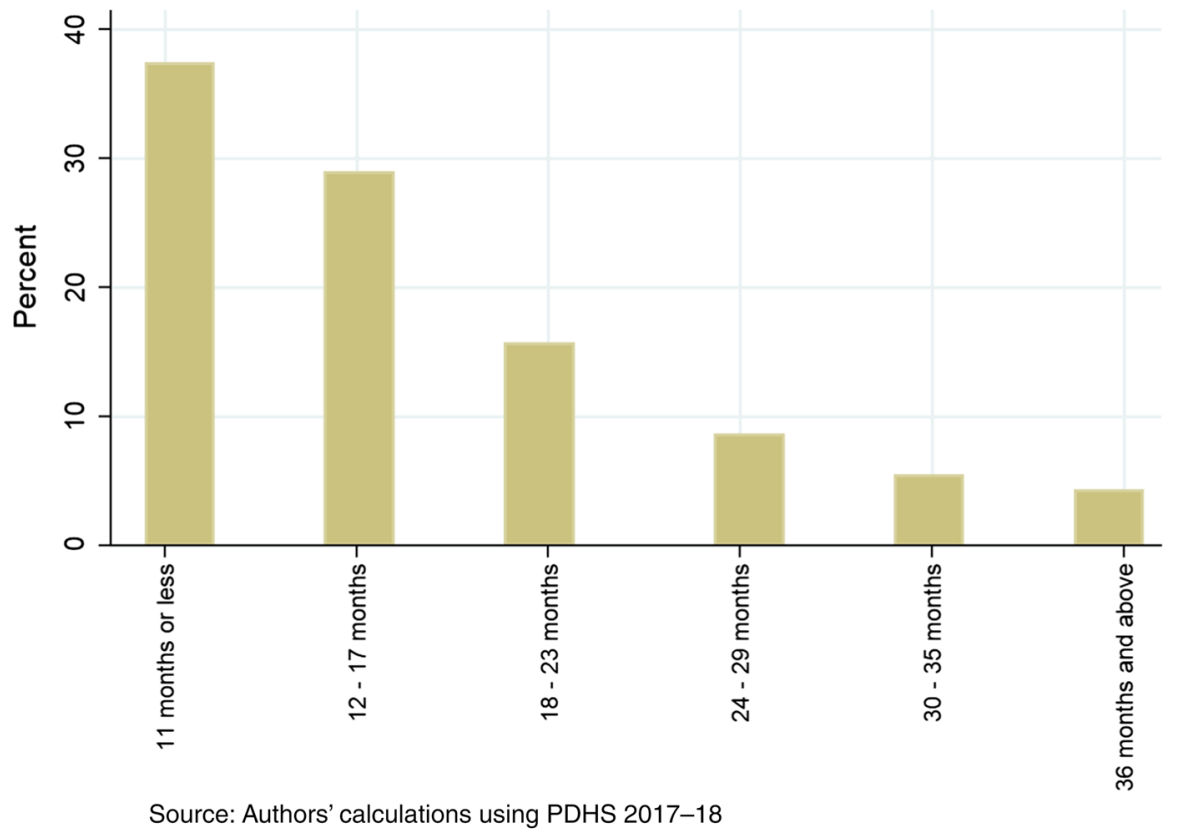

Fig. 2 Interval between marriage and first birth (2013-2017)

reported to be the three months in which the highest share of marriages traditionally takes place.

Along with seasonal variations, Pakistan's marriage calendar shows changing trends due to the shifting of the Hijri calendar. Pakistan's majority Muslim population usually does not celebrate marriages during the months of Muharram, the first month, and Ramadhan (also pronounced Ramzan), the ninth month. This cultural practice is more prevalent among the Muslims of the Indian Subcontinent and has little religious basis (Suleman, 1985).

The Islamic calendar is based on lunar observations and is about eleven days shorter than the solar calendar due to which, events based on the lunar calendar drift through the seasons. For instance, in 2013, the month of Ramadhan started on July 11. In 2017, it began on May 27, some 44 days earlier.

\section{Discussion}

Our approximate calculations based on the monthly mean of marriages from 2013 to 2017 show that the closure of marriage halls during the 14 March-14 September 2020 period concerns nearly half $(47.45 \%)$ of the marriages that were to take place during the year. This involuntary delay in nuptiality, which may range from a few days at the minimum, to six months or more, is bound to have a non-negligible impact on subsequent fertility. In Pakistan, childbearing begins soon after marriage, and about 37 percent of Pakistani married women give birth to their first child 
within twelve months of marriage (Fig. 2). The number of babies born within the first year of marriage corresponds to about $6.6 \%$ of total births (833 out of 12,644 live births between 2013 and 2017 reported in PDHS 2017-18). A sizeable number out of these (around 400,000 births) may get delayed due to the Covid-19-related marriage delays. ${ }^{2}$

This impact may however prove to be temporary as these delayed births can be 'recuperated' in the second year of marriage. This would result in a minor baby bump in the latter half of 2021 as the newly-wed couples move to make up for lost time. There is also some anecdotal evidence suggesting that weddings did take place during summer with limited guests as many families consider it undesirable to postpone a wedding once the match has been made.

However, there are other reasons to suggest that the Covid-19 pandemic and the corresponding lockdowns may have affected new marriages and fertility. Inordinate delays, postponement of wedding arrangements and an atmosphere of stress and fear can exacerbate tensions that could ultimately cause engagements to break down. The economic hardship caused due to the lockdowns may force many people to postpone marriages even when restrictions on public gatherings are lifted. Nearly two months of economic closure during the first preventive lockdown hit economic activity particularly hard. Pakistan's growth rate in the financial year 2020-21 went into negative territory for the first time since $1952 .{ }^{3}$ Barring the agriculture sector (which was allowed to remain open so as not to interrupt the wheat harvest), most of the economy shut down during the first lockdown. Labourers, daily wage workers, street vendors and small shopkeepers went for weeks without work. The government provided relief to 12 million poor households (about a third of the population) through the Ehsas Emergency Cash programme (Government of Pakistan, 2020b). The cash assistance was later extended to cover 16.9 million households, or about half of the country's population. However, the financial assistance of Rs. 12,000 (approx. USD75) could only be enough to get the poor households through a few weeks of the lockdown. In addition to the extreme poor, a large proportion of middle-income households are engaged in work in the informal sector and have to rely upon their savings to cover their needs. A substantial number of Pakistani households also receive remittances from overseas. These remittances help the household accumulate assets (Ahmed et al., 2018) and save for dowry and wedding expenses. This source of income for many households is in jeopardy as tens of thousands of Pakistani workers based in the Gulf countries lost their jobs and returned home. A plausible consequence of these financial difficulties is that marriages may be postponed for some months while household finances get rebuilt.

Slow economic activity will also decrease employment generation, which will in turn affect the marriage prospects of the about 1.4 million persons of working age who enter the labour market each year (Najam \& Bari, 2017). In Pakistan, delay in

\footnotetext{
${ }^{2}$ based on a Crude Birth Rate (CBR) of 28.25 per 1000 population for the year and a population estimated at 212,215,030 in 2018 (World Bank, 2018).

3 The country recorded a growth of $-1.8 \%$ in the financial year 1952 (Pakistan Bureau of Statistics, 2020).
} 
marriage timing is coincidental to young people's greater job precariousness (Sultan et al., 2020). Matches are not made, or wedding ceremonies arranged as long as one or both of the future partners do not achieve job security. This argument is in line with the conclusion of Sobotka et al. (2011) who report that the most important reason why economic recession is likely to exert downward pressure on fertility in developed countries is the rise in unemployment and job instability, which particularly affects young adults. Low-educated men with precarious work positions face more difficulties finding a partner with whom to start a family. In Pakistan, a greater focus on higher education and economic pressures are increasingly leading to late marriages. The ongoing economic slowdown may accentuate this trend.

Another reason for the postponement of marriages, especially those involving participants from overseas, might be the travel difficulties that the guests or even the marrying couple faced during the spring and summer of 2020. The pandemic was hitting hard the states of Persian Gulf, North America and Western Europe, and travel to Pakistan from these major destinations by Pakistani migrants was far below average. Consequently, many marriages had to be put off.

The cumulative effect of delayed marriages for all these reasons would be a significant delay in childbirth. This impact may however be dampened by modifications in the fertility behavior of the existing couples. The lockdown can lead to higher frequency of sexual intercourse as a result of couples being cloistered together. This, along with the fact that less than one in two couples in Pakistan use contraceptives, ${ }^{4}$ can imply a mini corona-baby boom in late 2020 and 2021. A survey from Italy found no support for this assertion as $81.9 \%$ of people surveyed in a study do not plan to conceive during the COVID-19 crisis (Micelli et al., 2020). Similarly, the desire to replace the deceased (replacement fertility) may not prove to be an overwhelming factor given low fatalities relative to the population. The lockdown may even act negatively on existing couples' fertility intentions as couples may choose to postpone their fertility plans in the environment of uncertainty and negative perceptions about the future (Menken et al., 1981). The existing couple's sexual activity and reproductive behavior may also suffer from increased risk of intimate partner violence and conflict (Sarkar, 2008).

The presence of these divergent directions that the fertility behaviour of existing couples may take, as well as the previously mentioned birth effects of delayed marriages, will ultimately determine the net fertility impact of the Covid-19 outbreak. A nation-wide demographic survey in the coming months may shed light on the various ways in which the Covid-19 pandemic affected the marital and birth patterns of Pakistani households.

Acknowledgements We would like to thank the Guest Editor Dr. Jeromey Temple and three anonymous referees for their constructive feedback. All the errors in the paper are our own.

\footnotetext{
4 According to the 2017-18 DHS, the country's Contraceptive Prevalence Rate (CPR) is $34 \%$.
} 


\section{References}

Ahmed, J., Mughal, M., \& Klasen, S. (2018). Great expectations? Remittances and asset accumulation in pakistan. Journal of International Development, 30(03), 507-532. https://doi.org/10.1002/jid.3202

Atkeson, A. (2020). What Will Be the Economic Impact of COVID-19 in the US? Rough Estimates of Disease Scenarios. In NBER Working Paper (No. 26867). https://doi.org/10.1017/CBO9781107 415324.004

Chandra, S., \& Christensen, J. (2019). RE: "Reassessing the Global Mortality Burden of the 1918 Influenza Pandemic.” American Journal of Epidemiology, 199(07), 1404-1406.

Government of Pakistan. (2020b). Ehsas programme, Poverty Alleviation and Social Safety Division. https://www.pass.gov.pk/Detailf90ce1f7-083a-4d85-b3e8-60f75ba0d788

Government of Pakistan. (2020a). Coronavirus tracker. http://covid.gov.pk/

IMF. (2020). The Great Lockdown: Worst Economic Downturn Since the Great Depression, IMF Blog by Gita Gopinath. https://blogs.imf.org/2020/04/14/the-great-lockdown-worst-economic-downturnsince-the-great-depression/

Johns Hopkins University \& Medicine. (2020). Mortality Analyses.

Johnson, N. P. A. S., \& Mueller, J. (2002). Updating the accounts: Global mortality of the 1918-1920 "Spanish" influenza pandemic. Bulletin of the History of Medicine, 76(1), 105-115. https://doi.org/ 10.1353/bhm.2002.0022

McKibbin, W. J., \& Fernando, R. (2020). The Global Macroeconomic Impacts of COVID-19: Seven Scenarios. In CAMA Working Paper Series. https://doi.org/10.2139/ssrn.3547729

Menken, J., Trussell, J., \& Watkins, S. (1981). The nutrition fertility link : An evaluation of the evidence a link between nutrition and fertility has. Human Fertility, 11(3), 425-441.

Micelli, E., Cito, G., Cocci, A., Polloni, G., Russo, G. I., Minervini, A., Carini, M., Natali, A., \& Coccia, M. E. (2020). Desire for parenthood at the time of COVID-19 pandemic: An insight into the Italian situation. Journal of Psychosomatic Obstetrics and Gynaecology. https://doi.org/10.1080/01674 82X.2020.1759545

Najam, A., \& Bari, F. (2017). Pakistan - National Human Development Report 2017. Pakistan: In United Nations Development Programme.

Pakistan Bureau of Statistics. (2020). Macro Economic Indicators. http://www.pbs.gov.pk/sites/default/ files//tables/Table-1_0.pdf

Patterson, K. D., \& Pyle, G. F. (1991). The geography and mortality of the 1918 influenza pandemic. Bulletin of the History of Medicine, 65(1), 4-21.

Sarkar, N. N. (2008). The impact of intimate partner violence on women's reproductive health and pregnancy outcome. Journal of Obstetrics and Gynaecology, 28(3), 266-271. https://doi.org/10.1080/ 01443610802042415

Sobotka, T., Skirbekk, V., \& Philipov, D. (2011). Economic recession and fertility in the developed world. Population and Development Review, 37(2), 267-306. https://doi.org/10.1111/j.1728-4457. 2011.00411.x

Spreeuwenberg, P., Kroneman, M., \& Paget, J. (2018). Reassessing the global mortality burden of the 1918 influenza pandemic. American Journal of Epidemiology, 187(12), 2561-2567. https://doi.org/ 10.1093/aje/kwy191

Suleman, M. (1985). MicrOfilms International Epidemiology of malaria in Punjab, Pakistan: a case study in a rural community near Lahore (Doctoral dissertation).

Sultan, T., Ahmad, S., \& Ayub, A. (2020). At risk of "leftover singles": Dimensions and sociopsychological repercussions of delayed marriageability among educated females in Pakistan. The Family Journal. https://doi.org/10.1177/1066480720902454

Taubenberger, J. K., \& Morens, D. M. (2006). 1918 Influenza: The mother of all pandemics. Emerging Infectious Diseases, 12(1), 15-22. https://doi.org/10.3201/eid1209.050979

World Bank. (2018). World Development Indicators (WDI). https://data.worldbank.org/country/pakistan World Bank. (2019). World Development Indicators (WDI). https://data.worldbank.org/country/pakistan

Publisher's Note Springer Nature remains neutral with regard to jurisdictional claims in published maps and institutional affiliations. 